\title{
Momento escola, momento ócio: as muitas faces do desenvolvimento humano ${ }^{1}$
}

\author{
Mônica de Carvalho Magalhães Kassar*
}

\begin{abstract}
Resumo
Este artigo apresenta reflexões a respeito das possibilidades de desenvolvimento cultural de alunos com Transtorno do Espectro Autista, não claramente explícitas em ambiente escolar. Para isso, analisa ocorrências em situações diferentes de uma mesma criança com diagnóstico de TEA: na escola e em situação de ócio, sob a luz da perspectiva histórico-cultural. O material para análise foi fornecido pela família do aluno especificamente para este estudo. Conclui-se que a escola tem ignorado possibilidades de desenvolvimento dos alunos, já expressos em situações fora da instituição escolar, e a perspectiva utilitarista presente na organização atual das instituições escolares contribui para manutenção dessa situação.

Palavras-chave: TEA; Autismo; Desenvolvimento cultural; Educação inclusiva; Educação especial.
\end{abstract}

\section{Momento escuela, momento ocio: las muchas facetas del desarrollo humano}

\section{Resumen}

Este artículo presenta reflexiones respecto al desarrollo cultural de alumnos con Trastorno del Espectro Autista, que no suelen estar claramente explícitos en el ambiente escolar. Para ello, analiza casos en situaciones diferentes de un mismo niño con diagnóstico de Trastorno del Espectro Autista: en la escuela y en situación de ocio, bajo la perspectiva histórico-cultural. El material para los análisis fue donado por la familia del alumno específicamente para este estudio. Se concluye que la escuela ha ignorado posibilidades de desarrollo de los alumnos, ya expresados en situaciones fuera de la institución escolar, y la perspectiva utilitarista presente en la organización actual de las instituciones escolares contribuye a mantener esa situación.

Palabras clave: TEA, autismo, desarrollo cultural, educación inclusiva, educación especial

\section{Moment school, moment idleness: the many faces of human development}

\begin{abstract}
This article presents some reflections about the possibilities of cultural development of students with Autism Spectrum Disorder, not clearly stated in the school environment. For this, it analyzes occurrences in different situations of one child diagnosed with ASD: at school and in an idle situation, in the light of the historical-cultural perspective. The material for analysis was provided by the student's family specifically for this study. It is concluded that the school has ignored possibilities of student development, already expressed in situations outside the school institution, and the utilitarian perspective present in the current organization of school institutions contributes to maintain this situation.
\end{abstract}

Keywords: ASD, autism, cultural development, inclusive education, special education

\section{Introdução}

Nas últimas décadas, assistimos à disseminação do propósito de construir escolas ou sistemas inclusivos em diferentes países. Nesse quadro, há o desafio compartilhado em oferecer educação escolar para crianças com características de diferentes ordens: orgânica, cultural, étnica, religiosa, entre outras.

Com foco específico em pessoas com deficiências, um relatório da Organização Mundial de Saúde de 2011 (WHO, 2011) oferece uma avaliação da situação global de atendimento às necessidades dessa população. Em relação à educação, o relatório ressalta o artigo 24 da Convenção dos Direitos das Pessoas com Deficiências (CRPD, 2006), que enfatiza a necessidade de os governos garantirem acesso igual a um sistema de educação inclusivo em todos os níveis, com suporte e apoio necessários às pessoas com deficiência para possibilitar sua escolarização. $\mathrm{O}$ relatório apresenta, ainda, um levantamento das condições de matrículas desses alunos no mundo, dividindo-as nas situações de escolas especiais, classes especiais em escolas integradoras e classes inclusivas. Por esse levantamento, fica evidente que a opção de construção de sistemas educacionais inclusivos voltados ao acolhimento de alunos com 
deficiências não é adotada igualmente em todos os países ${ }^{2}$.

Especificamente no Brasil, desde 2003, há o direcionamento claro para a construção de um "sistema educacional inclusivo" (BRASIL, 2004, 2008), que é entendido pelo Governo Federal como a garantia da matrícula dos alunos em salas de aulas comuns/regulares e, quando necessário, acompanhada do oferecimento de apoio de atendimento educacional especializado em turno oposto à escolarização obrigatória. Como decorrência dessa diretriz, há um movimento crescente de matrículas de alunos da Educação Especial $^{3}$ em salas de aulas comuns de escolas públicas e privadas em todo o país (REBELO; KASSAR, 2018).

Nas escolas comuns, os alunos (todos) têm encontrado o avanço de uma perspectiva em que o importante na escolarização é a aprendizagem de conhecimentos "úteis", aspecto este traduzido especialmente nas disciplinas de língua materna e matemática, que serão aferidos pelas avaliações de larga escala, sejam elas locais, nacionais ou internacionais. As disciplinas consideradas úteis também são aquelas que poderão ser aproveitadas pelos alunos em um futuro/hipotético ingresso ao mercado de trabalho.

Nesse ambiente, há a desconsideração de disciplinas abalizadas como menos importantes (especialmente aquelas não ligadas ao setor produtivo) e, muitas vezes, há também a supervalorização dos alunos classificados como mais capazes em detrimento dos que não são assim considerados. Kennedy e Power (2017), em estudo desenvolvido com alunos de escolas de elites irlandesas, relatam o processo de exclusão interno à escola baseado na meritocracia, processo este que não é desconhecido por escolas brasileiras, sejam elas privadas ou públicas. Os autores, em interlocução com McNamee e Miller (2004 apud KENNEDY; POWER, 2017), explicam que os aspectos percebidos como determinantes para o sucesso, por essa perspectiva, geralmente são "o talento inato, o trabalho árduo e a atitude correta e a virtude moral" (p. 225). O pensamento que sustenta essa perspectiva é o de que uma sociedade meritocrática é mais justa e produtiva; é um lugar onde distinções baseadas em critérios como classe, raça e gênero são diminuídas com o tempo (MCNAMEE; MILLER, 2004 apud KENNEDY; POWER, 2017).

Entende-se, pois, que se o mérito é individual e justo, boas práticas devem ser premiadas e as más punidas e, assim, sustentam-se as ações denominadas de responsabilização (FREITAS, 2012), sejam estas direcionadas às escolas, aos gestores, aos professores e mesmo, de alguma forma, aos alunos. Essa é a escola em que os alunos da Educação Especial estão matriculados e seguindo seus estudos. Nesse meio, como parte desses alunos é vista e percebida como aluno especial, aluno da inclusão ou o incluído, o ensino a ele direcionado é, em geral, diferenciado; mais fraco, mais lento, mais simples, mais repetitivo, características encontradas nas classes especiais de outrora (KASSAR, 1995), já que frequentemente esses alunos não participam de tais avaliações (CARDOSO; MAGALHÃES, 2012; SILVA, 2013; SILVA; MELETTI, 2014; SANTIAGO; SANTOS; MELO, 2017).

Se a situação de estar matriculada, portanto tornar-se aluno/a, é alcançada pela criança, nem sempre pode ser confirmado seu aproveitamento escolar, uma vez que diferentes trabalhos mostram que apesar da frequência escolar, muitos alunos não recebem atenção adequada em sala e comumente têm acesso a atividades restritivas e resumidas em relação ao material oferecido aos outros alunos (PLETSCH, 2010; SOUZA, 2013; REBELO; KASSAR, 2014).

Diante desse cenário, os propósitos deste artigo são evidenciar aspectos do desenvolvimento cultural de um aluno da Educação Especial, não claramente explícitos em ambiente escolar, e apontar possibilidades de superação de limitações escolares, sob a luz da perspectiva histórico-cultural. Para isso, analisamos ocorrências em situações diferentes, na escola e em situação de ócio, de uma mesma criança. Ócio, aqui, refere-se ao espaço/tempo do "não trabalho", em que a experiência é desprendida de uma utilidade prática, algo que se aproxima da criação, da contemplação e do prazer estético (MASCARENHAS, 2005) ${ }^{4}$.

O material para análise foi fornecido pela família do aluno especificamente para este estudo ${ }^{5}$.

\section{A criança e a literatura}

Pedro (nome fictício), no momento em que elaborou o material deste estudo, estava com 10 anos de idade e frequentava o $6^{\circ}$ ano do ensino fundamental em uma escola regular/comum privada. Ele é aluno dessa escola desde a educação infantil e demonstra sentir-se bem nesse espaço, onde é encorajado a participar de todas as atividades acadêmicas. Como se interessa por música, a família o inscreveu em aulas de piano em horário diferente ao escolar. Em sua casa, Pedro tem acesso livre ao 
piano e ao violão da família e a diferentes instrumentos de tecnologia de informação e comunicação (tablet, telefone celular, computador de mesa).

Ele é uma criança com diagnóstico de Autismo e apresenta as peculiaridades arroladas pela literatura especializada, dentro do quadro atualmente denominado de Transtorno do Espectro Autista (TEA). Schmidt (2012) apresenta a definição desse quadro proposta pelo Manual Estatístico de Transtornos Mentais, atualizado em 2000, DSM-IVTR, que entende que a situação de Autismo compõe a categoria dos Transtornos Globais do Desenvolvimento (TGD), e afeta três dimensões do desenvolvimento humano: "1) habilidades de interação social recíproca; 2) habilidades de comunicação; e 3) presença de comportamentos, interesses e atividades estereotipadas", (p 2). Nesse grupo, estariam incluídos também a Síndrome de Rett, o Transtorno Desintegrativo da Infância, a Síndrome de Asperger e Transtorno Invasivo do Desenvolvimento sem outra Especificação (TID$\mathrm{SOE})$, "sendo o autismo o transtorno prototípico desta categoria" (p. 3). Essas características aproximam-se às apresentadas na décima revisão da Classificação Internacional de Doenças, CID 10 (ou International Statistical Classification of Diseases and Related Health Problems - ICD), expostas em Tamanaha, Perissinoto e Chiar (2008). Assim, o Autismo Infantil tem sido "caracterizado por um desenvolvimento anormal ou alterado, manifestado antes dos três anos, apresentando perturbação do funcionamento nas áreas: interação social, comunicação e comportamento repetitivo" (TAMANAHA; PERISSINOTO; CHIAR, 2008, p. 298).

Lima e Laplane (2016, p. 270) acrescentam que o que antes foi denominado de Transtornos Globais do Desenvolvimento no DSM IV agora é conhecido como Transtornos do Espectro do Autismo ou TEA. Nunes, Azevedo e Schimdt (2013) registram que em 2013, a American Psychiatric Association (APA) propôs a adoção da nova terminologia, enquadrando-a a uma categoria denominada Transtornos do Neurodesenvolvimento. O TEA vem sendo entendido, então, como um distúrbio do desenvolvimento neurológico, presente desde a infância e que apresenta déficits nas dimensões sócio comunicativa e comportamental.

Lima e Laplane (2016, p. 270) explicam que

A nova denominação corresponde a uma mudança na conceituação do transtorno, que reduz os três domínios anteriormente considerados (prejuízo qualitativo na interação social, na comunicação e padrões restritos e repetitivos de comportamento, interesses e atividades) para dois: déficits sociais e de comunicação e interesses fixados e comportamentos repetitivos.

As autoras observam que a mudança tem o objetivo, segundo a APA (2013), de facilitar o diagnóstico e "situar numa linha continua traços ou características distribuídos em níveis de severidade para auxiliar a provisão dos apoios necessários para o desenvolvimento" (LIMA; LAPLANE, 2016, p. 270).

Como relatado em Delfrate, Santana e Massi (2009), a literatura especializada faz referências a características que podem estar presentes nas pessoas com o diagnóstico de TEA, como

[...] dificuldades no uso funcional da linguagem. Seus enunciados não são contínuos e ela tem dificuldade em engajar uma conversa, em fornecer informações, e principalmente em expressar suas ideias. Na maioria dos casos ela parece não saber o que são e para que servem as palavras (DELFRATE; SANTANA; MASSI, 2009, p. 323).

Outra característica apresentada em estudos difundidos é a que, segundo Schmidt (2012, p. 1) em interlocução com Blancher; Christensen (2011 apud SCHMIDT, 2012), mais chamou a atenção de Kanner na década de 1940: "inabilidade em estabelecer contato afetivo e interpessoal com outras pessoas". Nunes, Azevedo e Schimdt (2013) lembram que tais características podem levar ao isolamento da criança, de modo a empobrecer ainda mais suas habilidades comunicativas.

No Brasil, para efeitos legais, a Lei n. ${ }^{\circ}$ 12.764/2012 define a pessoa com Transtorno do Espectro Autista como aquela que possui uma síndrome clínica caracterizada nas formas descritas nos incisos I ou II:

I - deficiência persistente e clinicamente significativa da comunicação e da interação sociais, manifestada por deficiência marcada de comunicação verbal e não verbal usada para interação social; ausência de reciprocidade social; falência em desenvolver e manter relações apropriadas ao seu nível de desenvolvimento;

II - padrões restritivos e repetitivos de comportamentos, interesses e atividades manifestados por comportamentos motores ou verbais estereotipados ou por comportamentos sensoriais incomuns; excessiva aderência a rotinas e padrões de comportamento ritualizados; interesses restritos e fixos. (BRASIL, 2012) 
Os aspectos que envolvem interações diretas entre a criança e outro ser humano encontram limites nas pessoas com TEA, visto que este traço é considerado uma das características mais evidentes.

\section{A criança e a escola}

As características descritas acima têm sido identificadas por diferentes trabalhos como anomalias qualitativas, e, ante elas, profissionais têm diferentes visões sobre as formas e os locais mais adequados para a escolarização de crianças e jovens com diagnóstico de TEA. Há pesquisadores que entendem que metodologias específicas para esses alunos, como TEACCH ${ }^{6}$ e o Currículo Funcional Natural $^{7}$ (BOETTGER et al., 2013), seriam as mais adequadas. Por esta perspectiva, um ensino especializado em escolas que implantem adequadamente tais procedimentos seria o mais proveitoso. No entanto, pesquisas sobre esses métodos também não encontram unanimidade (VIRUES-ORTEGA; JULIO; PASTORBARRIUSOC, 2013). Por outra, há estudos que indicam que, a despeito da ocorrência de adversidades nas escolas comuns, como baixa progressão escolar, não acompanhamento do currículo e problemas com socialização, estas seriam os estabelecimentos de ensino mais adequados à criança com TEA, inclusive pela exposição dos alunos a diferentes alternativas metodológicas (GOMES; MENDES, 2010).

Como afirmam Nunes, Azevedo e Schimdt (2013, p. 558), "a escola se constitui como um recurso fundamental para enriquecer as experiências sociais das crianças com TEA, oportunizando a interação entre pares e contribuindo para o desenvolvimento de novas aprendizagens e comportamentos". Esse ponto de vista encontra suporte em estudos como o descrito por Parsons et al. (2009), que teve o propósito de verificar uma possível existência de metodologias mais apropriadas e efetivas para alunos com autismo. Para tanto, inventariaram pesquisas realizadas no Reino Unido e na Irlanda, entre 2002 e 2008, e verificaram que não há evidências de haver um único tipo mais apropriado de intervenção com essa população. Por fim, recomendam que um conjunto de possibilidades educacionais deva ser mantido para atender apropriadamente a uma ampla diversidade de necessidades.

Estes e outros trabalhos nos direcionam a afirmar que o desafio da escolarização de alunos com TEA vai além da matrícula, já que a frequência escolar não implica, necessariamente, seu status integral de aluno, com acesso ao conhecimento e desfrute de todas as atividades escolares. Dentre os diferentes trabalhos acerca dessa temática, há um grupo de investigações que nos parece bastante promissor, por construir seus estudos a partir da assunção de que características apresentadas por essas crianças, vistas por alguns pesquisadores como marcas de sua patologia, podem ser tomadas como indício de desenvolvimento. Nessa perspectiva estão trabalhos como o de Delfrate, Santana e Massi (2009) ou de Schimdt (2012).

Delfrate, Santana e Massi (2009), em pesquisa sobre aquisição de linguagem de uma criança com autismo, desenvolvem uma intervenção com o intento de entender as características linguísticas "não se levando em conta o que ela não tem, e sim, procurando-se entender o que ela consegue apreender do mundo e das interações, apesar de suas particularidades" (p. 323-324). As autoras consideram formas linguísticas geralmente vistas como características do TEA, portanto parte da patologia, como indícios "da entrada da criança na linguagem, quando se analisa a linguagem na interação. Logo, a interação é peça chave na construção da linguagem, pois é nela que ocorrem as práticas dialógicas" (p. 330-331), lembrando que a criança está imersa na língua e não fora dela. Como afirmam as autoras: "A ecolalia, por exemplo, não pode ser analisada apenas como sintoma patológico, como se não fosse também encontrada no discurso dito normal. Essa repetição aparece também no processo normal de aquisição de linguagem". (DELFRATE; SANTANA; MASSI, 2009, p. 324).

Em perspectiva próxima, Schmidt (2012) também usa o exemplo da linguagem e afirma que

"a fala recortada e colada da letra de determinada música pode ser tomada pelo professor como uma manifestação de ecolalia deferida, ou seja, como algo não intencional ou comunicativo, apenas repetitivo, portanto, sem sentido. Porém, esse comportamento também pode ser entendido como uma forma legítima daquele sujeito expressar-se, considerando sua singularidade, e que é revestida de intenção comunicativa". (SCHMIDT, 2012, p. 5, grifos do autor)

Schmidt, em interlocução com Baptista e Bosa (2002), defende que investir nessa busca pode "resultar na descoberta de particularidades que hão de servir como importantes chaves de acesso à constituição da subjetividade desse sujeito, indicando caminhos com novas possibilidades de 
intervenções pedagógicas customizadas" (SCHMIDT, 2012, p. 5-6, grifos do autor).

O mesmo pode ser generalizado a outros comportamentos específicos da pessoa com autismo que podem ser entendidos pelo professor como falta (de intenção, comunicação ou até vontade) ou simplesmente como uma maneira diferente de ser/estar e que exige uma mudança paradigmática no entendimento. (SCHMIDT, 2012, p.6)

Sob uma óptica semelhante, Dainez e Smolka (2014) ressaltam que é importante mudar a concepção que direciona o trabalho educativo da criança com deficiência, orientando "o olhar não para o defeito, mas para a pessoa como um todo, pensando a sua integralidade nas condições de vida e educação recebidas, na complexidade de seu funcionamento, nas suas possibilidades" (DAINEZ; SMOLKA, 2014, pp. 1097-1098).

A considerar essa diretriz, apoiada na perspectiva histórico-cultural, mais especificamente em trabalhos de Vygotsky, podemos ver as produções escolares de Pedro no ambiente escolar, onde frequenta todas as disciplinas com a turma e recebe atenção diferenciada dos docentes das disciplinas em alguns momentos. Suas tarefas escolares seguem a mesma programação que de seus colegas, mas com exercícios diferenciados, sendo de modo geral mais objetivos e/ou resumidos.

FIGURA 1: Proliferação do mosquito da dengue (Ciências)

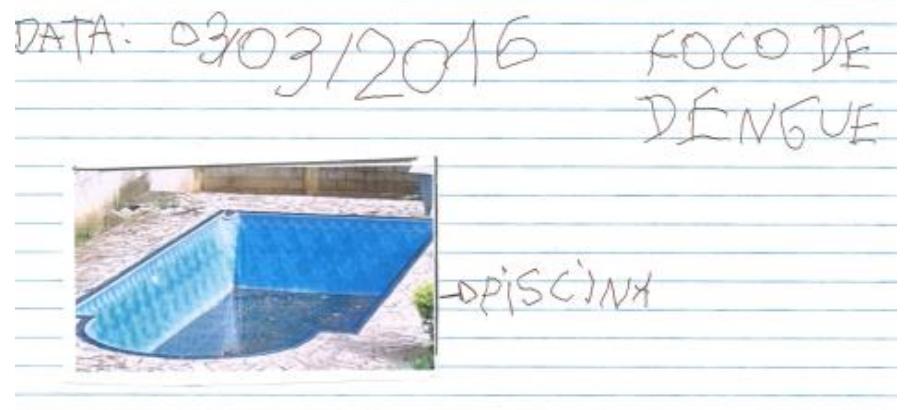

Fonte: Material escolar do aluno.

FIGURA 2: Estilos de linguagem (Língua portuguesa)

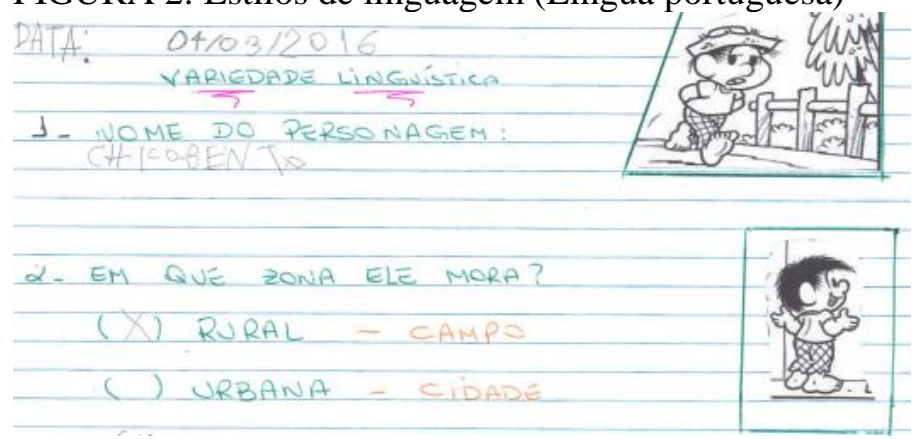

Fonte: Material escolar do aluno.

Nestas e outras atividades escolares é possível verificar que Pedro responde positivamente as atividades propostas pela escola, faz uso da língua escrita e domina a leitura. No entanto, essas tarefas são marcadas por certa simplicidade e/ou facilidade se comparadas às atividades comuns a alunos de $6 .^{\circ}$ ano do ensino fundamental.

$\mathrm{O}$ oferecimento de trabalhos escolares simplificados a alunos da Educação Especial ocorre com certa frequência. Pesquisas como as desenvolvidas por Pletsch, (2010), Carvalho (2013), Rebelo; Kassar (2014) no Brasil ou como as de Muñoz (2008) ou Gonzalez (2010), em outros países, sinalizam a existência, nas escolas, de expectativas restritas em relação ao desenvolvimento escolar desses alunos, especialmente daqueles que têm diagnóstico de deficiência intelectual e os classificados dentro do conjunto de TGD, fato que 
explicaria a simplificação das tarefas escolares. As restrições, por sua vez, estão presentes em parte da literatura específica, que considera o diferente como patológico e não como apenas outra forma de interagir com o mundo, como já registrado neste texto. Nesse panorama, é provável que as produções escolares de Pedro, com suas características simples e objetivas, sejam vistas como demonstrativas de traços de sua patologia.

\section{A criança e o ócio}

Em casa, como já mencionado, Pedro demonstra interesse por música (clássica e de MPB) e instrumentos de tecnologia de comunicação e informação, sendo um dos passatempos comuns o uso de diferentes softwares no computador da família. Dentre as brincadeiras, Pedro cria músicas e filmes usando os instrumentos a sua disposição.

Para este artigo, escolhemos um dos produtos criados por Pedro: um vídeo de aproximadamente cinco minutos, gravado no aparelho celular da família.

\section{Fases da confecção do filme}

Pedro solicitou a sua mãe que desenhasse em papeis do tipo A4, com canetas coloridas, figuras específicas: um navio, um avião, um globo terrestre com o continente americano, um foguete, entre outras cosias. Posteriormente, orientou-a que repetisse alguns desenhos, mas sem a utilização de cores, que os fizesse "apagados". Durante a elaboração dos desenhos, Pedro deu orientações precisas, inclusive, descartando alguns trabalhos que ele julgou inadequados. Quando considerou concluída essa fase, Pedro ficou sozinho e iniciou uma gravação com o aparelho celular, os desenhos em papel e alguns bonecos. Iniciava uma gravação, ria, e recomeçava.

Após quatro ou cinco tentativas, Pedro considerou pronto seu trabalho; trata-se de uma sequência preparada autonomamente para a música Aquarela (dos autores Toquinho, Vinícius de Moraes, M. Fabrizio e G. Morra). O vídeo inicia com um ajuste de tom, com a voz de Pedro, que passa a cantar a música integralmente, com letra e melodia adequadas. A música é acompanhada pelos desenhos elaborados em papel, que ele filma na sequência exata em que a música se refere a determinadas situações. Além dos desenhos, Pedro também utiliza os bonecos para a representação dos "alguns bons amigos”. Na sequência final da música, há:
Vamos todos

Numa linda passarela

De uma aquarela que um dia enfim

Descolorirá

Numa folha qualquer

Eu desenho um sol amarelo

Que descolorirá

E com cinco ou seis retas

É fácil fazer um castelo

Que descolorirá

Giro um simples compasso

E num círculo eu faço o mundo

Que descolorirá

Enquanto canta esses refrãos, Pedro mostra o desenho de uma passarela com cores ao lado de uma passarela sem cor (apagada, "que descoloriu"), depois mostra o desenho do sol amarelo, ao lado do sol apagado e assim sucessivamente até o final da música, evidenciando a compreensão da sutileza da letra da música.

O trabalho desenvolvido autonomamente por Pedro em sua situação de ócio é qualitativamente diferente dos que ele desenvolveu até então em situação escolar. A elaboração do vídeo de Pedro necessitou de planejamento anterior à execução do projeto, liberdade para o uso dos materiais (folhas de papel, canetas, tesoura, aparelho celular, etc.), colaboração quando solicitada (à mãe), o controle e o uso adequados dos artefatos, a memória para letra e melodia, a interpretação adequada das situações descritas na letra da música e da sutileza da representação das alterações de situações propostas na letra (que descolorirá...).

A criação de Pedro foi possível, dentre outros aspectos, pela utilização de instrumentos (a tesoura, as canetas, o aparelho celular, os bonecos, etc.). Como argumenta Pino (1994), instrumentos são criações humanas e como tais, são carregados de significado, pois já trazem em si a "intenção" da ação, antecipando de alguma forma as possibilidades de seus usos (PINO, 1994). Pedro, ao utilizar tais instrumentos, mostra a apropriação dos significados socialmente atribuídos a eles, além de criar novas situações, como o uso dos bonecos como personagens de seu filme. Como desenvolvido por Kassar (1999; 2013), a criação e a utilização de instrumentos, sejam internos (linguagem) ou externos, marcaram de forma contundente a condição humana (ENGELS, 1979), provocando mudanças substanciais na construção do conhecimento. No desenvolvimento de um indivíduo em particular, esse 
processo também ocorre, possibilitando que o sujeito entre no mundo humano, quando utiliza instrumentos já existentes, e colabore com novas criações.

Outro aspecto a ser ressaltado na realização da atividade de Pedro é a presença de caminhos indiretos (uso de todos os instrumentos e procedimentos). Vigotski apresenta o desafio de fazer adições em crianças pequenas: ao ser inquerida sobre o resultado de $6+2$, por exemplo, a criança utiliza seus dedos para dar a resposta adequada. Para o autor, a utilização desse procedimento indica a estrutura de um caminho indireto para a realização de determinada operação: "Nesse caso, as mãos, que não possuem relação direta com a pergunta, adquirem significado de instrumento assim que a execução da tarefa pelo caminho direto se mostra impedida para a criança" (VIGOTSKI, 2011, p. 864). A criança apela aos caminhos indiretos quando os diretos são impossíveis; aí se configura a possibilidade de desenvolvimento cultural.

Um terceiro aspecto ainda pode ser verificado no filme elaborado por Pedro: mesmo que a criança tenha acesso a um significativo capital cultural (BOURDIEU, 2006) em casa, não é possível descartar que ele esteja também se apropriando de conceitos sistematizados na escola (o globo terrestre no espaço, a posição e as formas adequadas dos continentes, etc.).

\section{Implicações para o processo escolar}

Há diferentes possibilidades de olhar e explicar a experiência de Pedro com a música Aquarela. Uma poderia ser a perspectiva que privilegia a patologia e, a partir daí, afirmar que é uma das características de pessoas com TEA decorar trechos de músicas ou de filmes. Outra possibilidade é entender a experiência de Pedro como indicativa de um desenvolvimento em pleno movimento, em que diferentes funções cognitivas são postas em ação em um trabalho autônomo e inventivo. Nesse sentido, o filme de Pedro deve ser visto como uma criação, que abre possibilidades a ele, como autor, e aos outros, por exemplo, seus professores, que podem percebêlo como um ser humano em pleno desenvolvimento e passar a provocá-lo com atividades mais desafiadoras. Se, como afirmou Vygotsky, "cada minuto do homem está pleno de possibilidades não realizadas" (VYGOTSKY, 1991, p. 48), as possibilidades do desenvolvimento de uma pessoa são sempre maiores daquilo que se apresenta (KASSAR, 1999). As ações empreendidas por Pedro demonstram não só a existência de habilidades (ou funções psicológicas) já consolidadas, mas também a indicação de que vários processos cognitivos complexos estão em plena atividade.

O filme elaborado por Pedro é uma materialização da explicitação das várias possiblidades de seu desenvolvimento cognitivo/cultural. Ao considerar o produto por ele criado sob esta perspectiva, é possível sugerir o oferecimento de outras e diferentes práxis pedagógicas, sustentadas na certeza de que educação escolar também se relaciona ao desenvolvimento cultural/humano.

Vigotski afirmou que "o desenvolvimento das formas superiores de comportamento acontece sob pressão da necessidade; se a criança não tiver necessidade de pensar, ela nunca irá pensar" (VIGOTSKI, 2011, p. 866). Portanto, a escola que é restrita de possibilidades materiais/culturais/etc. e de desafios também é restrita de possiblidades de desenvolvimento para seus alunos. Na escola em que há como meta o desenvolvimento integral do indivíduo, não deve haver lugar para "passos lentos e tranquilos"; a escola deve ensinar a saltar (VIGOTSKI, 2011, p. 866), o que significa uma mudança radical no ponto de vista educacional.

A mudança de perspectiva na escola implica entender que o desenvolvimento não se dá por um processo homogêneo, nem por relações diretas, uma vez que "a estrutura das formas complexas de comportamento da criança consiste numa estrutura de caminhos indiretos" (VIGOTSKI, 2011, p. 864). Essa complexa relação é difícil de ser percebida no dia a dia escolar, uma vez que "o meio social, desde o início, oferece à criança uma série de caminhos indiretos, então, muito frequentemente, não percebemos que o desenvolvimento acontece por esse caminho indireto" (VIGOTSKI, 2011, p. 864). A mudança refere-se também à transformação da escola como lócus de atividades que ultrapassem o currículo "importante" (não o desconsiderando). Russel (1932), em seu O Elogio ao Ócio, defende que a educação deveria levar o homem mais longe do que normalmente faz e oferecer-lhe outras possibilidades para além das utilidades. Essa é a escola necessária a toda a criança, com ou sem qualquer deficiência.

\section{Considerações finais}

Iniciamos este artigo lembrando o desafio de construir uma escolarização adequada a todos os alunos em instituições escolares marcadas pela meritocracia, pela competição e pela 
responsabilização como características individuais, em que todo o processo escolar tem sido reduzido a uma perspectiva utilitarista do conhecimento. Como afirmado em Kassar (2013), a herança platônicacartesiana foi revigorada na constituição da divisão do trabalho fabril/industrial e imprimiu formas de ajuizamento sobre a atividade humana, de modo a instituir uma percepção simplista da divisão de trabalhos considerados manual e intelectual na sociedade. Nessa divisão, um grupo de pessoas é considerado mais capaz e a ele está direcionada a capacidade de desenvolvimento das atividades mentais complexas. Às pessoas com deficiências são atribuídas funções/atividades consideras mais simples. Essa forma de percepção está tão presente na sociedade em geral quanto na escola e, nessa instituição, revela-se, dentre outras circunstâncias, nas atividades simplificadas oferecidas aos alunos com deficiências.

$O$ foco na simplificação e a restrição da perspectiva do que é oferecido ao aluno, tenha ele ou não qualquer deficiência, restringe seu desenvolvimento. Vygotsky (1991) afirmava que "o comportamento se dá a partir de um sistema de reações triunfantes" (VYGOTSKY, 1991, p.47), e, nesse processo, deixa possibilidades não realizadas. No entanto, essas possibilidades não podem ser ignoradas, por constituírem, também, o produto da apropriação de cada indivíduo, produto de seu desenvolvimento (KASSAR, 1999).

Os diferentes espaços e experiências são fundamentais na vida das pessoas e nesses, apresentamos formas diversas de agir e interagir, a depender, dentre outros aspectos, das relações sociais. O vídeo faz supor que Pedro possui habilidades e conhecimentos que talvez ele não apresente na escola; e talvez a escola não solicite tanto dele. Como defendia Vigotski, o desenvolvimento de um indivíduo é sempre maior do que se apresenta e Pedro não foge à regra. No entanto, o movimento criativo de Pedro em casa não foi mostrado aqui como um parâmetro de atividades pedagógicas para a escola, mas como pista de que desafios maiores podem ser oferecidos aos alunos (com ou sem deficiências).

Ainda, é necessário ressaltar que a elaboração do filme por Pedro só foi possível pelas condições materiais à sua disposição em casa, condições estas que poderiam também estar nas escolas.

Especificamente às proposições de escolarização aos alunos com TEA, cabe registrar que pessoas com deficiências não se constituem um grupo homogêneo, mesmo aquele grupo que recebe uma mesma denominação (autista, por exemplo); enxergá-las sob o olhar da homogeneidade, muitas vezes, negligencia a diversidade e a riqueza de suas vidas cotidianas (SHAH; 2007). Por fim, é sempre bom lembrar que o desenvolvimento de pessoas ocorre na interação social, na apropriação de práticas sociais, na interação sujeito - sujeitos, de modo que as características atribuídas ao humano são construídas nessa relação (PINO, 2005). É assim, em todas as pessoas, inclusive com as pessoas com o diagnóstico de TEA. Alunos com autismo não apresentam, necessariamente, as mesmas características; as formas com que cada um deles aprende ou se sente melhor são tão amplas quanto às de quaisquer outras pessoas.

\section{Notas}

1 Uma versão bastante inicial dessa temática foi apresentada no $6^{\text {th }}$ International Congress of Educational Sciences and Development, ocorrido em Setúbal, Portugal, em junho de 2018.

2 Dos países europeus levantados no relatório, apenas Chipre, Islândia, Irlanda, Lituânia, Malta, Noruega, Portugal, Escócia, Eslovênia, Espanha, possuíam mais de $60 \%$ dos alunos da Educação Especial em situação de "inclusão", em 2011. (WHO, 2011).

3 Alunos com deficiências, transtornos globais do desenvolvimento e altas habilidades/superdotação - alunos da Educação Especial (BRASIL, 2008).

4 É relevante registrar os debates em torno dos significados de ócio e lazer nas sociedades contemporâneas, momento histórico/local em que nada escapa ao mercado e ao controle dos tempos e das formas de funcionamento. Para aprofundamento, ver Mascarenhas (2005).

5 Registro meus agradecimentos ao aluno e sua família pela generosidade na cedência deste material. Registro ainda que para o desenvolvimento deste estudo, os familiares foram formalmente consultados sobre a anuência em relação ao uso desse material para publicação acadêmica.

6 O TEACCH (Treatment and Education of Autistic and Related Communication Handicapped Children ou Tratamento e Educação de Crianças Autistas e com Perturbações da Comunicação) é um método de ensino estruturado utilizado majoritariamente com acrianças com TEA, desenvolvido pelo psicólogo Eric Schopler na Carolina do Norte (EUA), entre o final da década de 1960 e início de 1970 
(SCHOPLER; MESIBOV, 1988). A utilização desse método tem sido foco de uma polêmica, por ser defendido como o mais adequado às pessoas com TEA. Sobre esse debate, ver Menéndez (2012).

7 O Currículo funcional/natural (ou Currículo para a vida) visa ensinar às pessoas com deficiência habilidades que sejam funcionais (úteis), através de procedimentos naturais. Foi desenvolvido por Judith LeBlanc, da Universidade do Kansas (EUA). Para conhecimento, ver Leblanc (1982), Suplino (2005), Boettger et al. (2013) e Walter (2017).

\section{Referências}

BAPTISTA, Cláudio Roberto; BOSA, Cleonice. Autismo e Educação. 1a edição. Porto Alegre, Artmed, 2002.

BOETTGER, Andréa Rizzo dos Santos; LOURENÇO, Ana Carla; FIALHO, Messias; CAPELLINI, Vera Lucia. O professor da Educação Especial e o processo de ensino-aprendizagem de alunos com autismo. Revista Educação Especial, vol. 26, núm. 46, maio-agosto, 2013.

BOURDIEU, Pierre. Escritos de educação. Inserir edição. Vozes, 2006.

BRASIL. Secretaria de Educação Especial. Educação Inclusiva: direito à diversidade. Documento orientador. Brasília, 2004.

Política Nacional de Educação Especial na perspectiva da Educação Inclusiva. Brasília, DF, 2008.

Presidência da República. Casa Civil. Subchefia para Assuntos Jurídicos. Lei $n^{\circ} 12.764$, de 27 de dezembro de 2012. Institui a Política Nacional de Proteção dos Direitos da Pessoa com Transtorno do Espectro Autista; e altera o § 3o do art. 98 da Lei no 8.112, de 11 de dezembro de 1990.

CARDOSO, Ana Paula Lima Barbosa; MAGALHÃES, Rita de Cássia Barbosa Paiva. Educação Especial e avaliações em larga escala no município de Sobral (CE). Revista Educação Especial, v. 25, n. 44, p. 449-464, set./dez., 2012. CARVALHO, Maria de Fátima. O aluno com deficiência intelectual na escola: ensino, aprendizagem e desenvolvimento humano. In: MELETTI, S. M. F.; KASSAR, M.C.M. (Org.). Escolarização de Alunos Com Deficiências Desafios e Possibilidades. Campinas, SP: Mercado de Letras, 2013.

CRPD. Convention on the Rights of Persons with Disabilities. Geneva, United Nations, 2006.

Disponível em:

https://www.un.org/development/desa/disabilities/c onvention-on-the-rights-of-persons-withdisabilities.html. Acesso em: julho de 2018.

DAINEZ, Débora: SMOLKA, Ana Luiza Bustamante. O conceito de compensação no diálogo de Vigotski com Adler: desenvolvimento humano, educação e deficiência. Educ. Pesquisa, São Paulo, v. 40, n. 4, p. 1093-1108, out./dez. 2014.

DELFRATE Christiane de Bastos; SANTANA, Ana Paula de Oliveira; MASSI, Giselle de Athaíde. A aquisição de linguagem na criança com autismo: um estudo de caso. Psicologia em Estudo, Maringá, v. 14, n. 2, p. 321-331, abr./jun, 2009.

ENGELS, Friedrich Dialética da natureza. $3^{\mathrm{a}}$ edição. Rio de Janeiro: Paz e Terra, 1979. FREITAS, Luiz Carlos de. Os reformadores empresariais da educação: da desmoralização do magistério à destruição do sistema público de educação. Educação \& Sociedade, 33(119), 379404, 2012.

GOMES, Camila Graciella Santos.; MENDES, Enicéia Gonçalves. Escolarização inclusiva de alunos com autismo em Belo Horizonte. Revista Brasileira de Educação Especial. Marília, v.16, n.3, p.375-396, Set.-Dez., 2010.

GONZÁLEZ, José Antonio Torres. Pasado, presente y futuro de la atención a las necesidades educativas especiales: Hacia una educación inclusiva. Revista Perspectiva Educacional, Vol 49, N. ${ }^{\circ} 1,2010$.

KASSAR, Mônica de Carvalho Magalhães. Ciência e senso comum no cotidiano das classes especiais. Inserir edição. Campinas: Papirus, 1995.

Deficiência múltipla e educação no Brasil: discurso e silêncio na história de sujeitos. Campinas, Autores Associados, 1999. 
Funções mentais superiores e a formação da consciência em sujeitos com deficiência mental grave: implicações pedagógicas. In: SMOLKA, Ana Luiza Bustamante; NOGUEIRA, Ana Lúcia Horta. (Org.). Estudos na perspectiva de Vigotski: gênese e emergência das funções psicológicas. 1. ${ }^{\mathrm{a}}$ ed. Campinas: Mercado de Letras, 2013, v. 1, p. 151172.

KENNEDY, Margaret; POWER, Martin J. The Smokescreen of meritocracy: Elite Education in Ireland and the reproduction of class privilege. Journal for Critical Education Policy Studies, vol.8. n. ${ }^{\circ} .2,2010$.

LEBLANC, Judith. M. Enseñanza Funcional/Natural para la Generalización y Mantenimiento de las Habilidades para Niños com Autismo y Retardo Mental. Universidade de Kansas e Centro de Educação Especial Ann Sullivan, Peru. 1982.

LIMA, Stéfanie Melo; LAPLANE, Adriana Lia Friszman de. Escolarização de Alunos com Autismo. Revista brasileira de educação especial, Marília, v. 22, n. 2, p. 269284, jun. 2016.

MASCARENHAS, Fernando. Entre o ócio e o negócio: teses acerca da anatomia do lazer. Tese (Doutorado em Educação Física). Unicamp, 2005.MENÉNDEZ, Ramón. Autismo: uma questão de ciência ou de ideologia? Estudos de psicanálise, Belo Horizonte, , n. 38, p. 115124, dez. 2012.

MUÑOZ, Ximena Damm. Representaciones y actitudes del profesorado frente a la integración de Niños/as con Necesidades Educativas Especiales al aula común. Revista Latinoamericana de Educación Inclusiva, p.25-35, 2008. Disponível em: http://www.repositoriocdpd.net:8080/bitstream/hand le/123456789/78/Art_DammMunozX_Representaci onesActitudesProfesorado_2008.pdf?sequence $=1$. Acesso em julho de 2018

NUNES, Débora R. P.; AZEVEDO, M. Q. O.; SCHMIDT, C. Inclusão educacional de pessoas com Autismo no Brasil: uma revisão da literatura.

Revista Educação Especial, v. 26. n. 47, p. 557-572, set./dez, 2013.

PARSONS, Sarah; GULDBERG, Karen;
MACLEOD, Andrea; JONES, Glenys; PRUNTY, A.; BALFE, T. International review of the literature of evidence of best practice provision in the education of persons with autistic spectrum disorders. Ncse Research Reports N. ${ }^{\circ}$ 2. National Council for Special Education; An Chomhairle Náisiúnta um Oideachas Speisialta, University of Birmingham, 2009.

PINO, Angel Sirgado. A questão da significação: perspectiva histórico-cultural. II Congresso Brasileiro de Neuropsicologia. Texto mimeo. Campinas, 1994.

PINO, Angel Sirgado. As marcas do humano. As origens da constituição cultural da criança na perspectiva de Lev S. Vigotski. $1^{\text {a }}$ edição. São Paulo: Cortez, 2005.

PLETSCH, Márcia Denise. Repensando a inclusão escolar: diretrizes políticas, práticas curriculares e deficiência intelectual. $1^{a}$ edição. Rio de Janeiro: Nau: Edur, 2010.

REBELO, Alessandra Santos; KASSAR, Mônica de Carvalho Magalhães. Implantação de programas de educação inclusiva em um município brasileiro: garantia de efetivação do processo ensinoaprendizagem? Archivos Analíticos de Políticas Educativas / Education Policy Analysis Archives, p. 1-19, 2014.

REBELO, Alessandra Santos; KASSAR, Mônica de Carvalho Magalhães. Indicadores educacionais de matrículas de alunos com deficiência no Brasil (1974-2014). Estudos em Avaliação Educacional (Online), p. 1-276-307, 2018.

RUSSELL, Bertrand. In Praise of Idleness. The Anarchist Library. Topic: anti-work. Source: www.zpub.com, 1932. Disponível em: http://theanarchistlibrary.org/library/bertrandrussell-in-praise-of-idleness-11-02-05-22-00-46. Acesso em: setembro de 2018.

SANTIAGO, Mylene Cristina; SANTOS, Mônica Pereira dos; MELO, Sandra Cordeiro de Inclusão em educação: processos de avaliação em questão. Ensaio: avaliação e políticas públicas em Educação, Rio de Janeiro, v.25, n. 96, p. 632-651, jul./set. 2017.

SCHMIDT, Carlo. Transtornos do espectro do 
autismo na escola - protagonismos no processo inclusivo. 35. ${ }^{a}$ Reunião Nacional da ANPEd, [Anais]. 2012. Disponível em: http://w3.ufsm.br/edea/images/ARTIGOS/GT1 5-1786_int.pdf. Acesso em: julho de 2018.

SCHOPLER, Eric; MESIBOV, Gary B. (Eds.). Diagnosis and Assessment in Autism. New York: Springer Science; Business Media, 1988. SHAH, Sonali. Special or mainstream? The views of disabled students. Research Papers in Education. Vol. 22, No. 4, December, 2007, pp. 425-442.

SILVA, Mariana Cesar Verçosa. Avaliação em larga escala de alunos com necessidades educacionais especiais no município de Londrina-PR. Dissertação (Mestrado em Educação). UEL, Londrina, 2013.

SILVA, M. C. V.; MELETTI, Silvia Márcia Ferreira. Estudantes com necessidades educacionais especiais nas avaliações em larga escala: Prova Brasil e ENEM. Revista Brasileira de Educação Especial, v. 20, p. 53-68, 2014.

SOUZA, Flávia Faissal. Políticas de educação inclusiva: análise das condições de desenvolvimento dos alunos com deficiência na instituição escolar. 2013. 261p. Tese (Doutorado em Educação) - Faculdade de Educação, Universidade Estadual de Campinas, 2013.

SUPLINO, Maryse. Currículo funcional natural: guia prático para a educação na área do autismo e deficiência mental - Brasília: Secretaria Especial dos Direitos Humanos, Coordenadoria Nacional para a Integração da Pessoa Portadora de Deficiência; Maceió: ASSISTA, 2005.
TAMANAHA, Ana Carina; PERISSINOTO, Jacy: CHIARI, Brasilia Maria. Uma breve revisão histórica sobre a construção dos conceitos do Autismo Infantil e da síndrome de Asperger. Revista da Sociedade Brasileira de Fonoaudiologia. 2008;1 3(3):296-9.

VIGOTSKI, Lev Semyonovich A defectologia e o estudo do desenvolvimento e da educação da criança anormal. Tradução de Denise Regina Sales, Marta Kohl de Oliveira e Priscila Nascimento Marques. Educação e Pesquisa, São Paulo, v. 37, n. 4, p. 861-870, dez. 2011.

VIRUES-ORTEGA, Javier.; JULIO, Flavia.; PASTOR-BARRIUSO, Roberto. The TEACCH program for children and adults with autism: A meta-analysis of intervention studies. Clinical Psychology Review. Volume 33, Issue 8, December 2013, Pages 940-953. Disponível em: https://www.sciencedirect.com/science/article/pii/S0 272735813000937?via\%3Dihub. Acesso em: julho de 2018.

VYGOTSKY, Lev Semyonovich Consciencia como problema de la psicología del comportamiento. Obras Escogidas I. Madrid, Visor, Ministerio de Educación y Ciencia, 1991.

WALTER, Cátia Crivelenti de Figueiredo. Reflexões sobre o currículo funcional/natural e o PECS-Adaptado no processo de inclusão do aluno com autismo. Inclusão Social, Brasília, DF, v.10 n.2, p.132-140, jan./jun. 2017.

WHO. World report on disability 2011. The World Bank. WHO Library Cataloguing-in-Publication Data, 2011.

\section{Sobre a autora}

Mônica de Carvalho Magalhães Kassar possui graduação em Pedagogia pela Universidade Estadual de Campinas (1983), mestrado em Educação pela Universidade Federal de Mato Grosso do Sul (1993) e doutorado em Educação pela Universidade Estadual de Campinas (1999). Realizou estágios de pós-doutorado na Universidad de Alcalá (2005), na Universidade Estadual de Campinas (2011) e na Universidade de Lisboa (2017 a 2018). É colaboradora do Centro de Estudos em Educação e Sociedade (CEDES) e professora associada da Universidade Federal de Mato Grosso do Sul. Tem experiência na área de Educação, com ênfase em educação especial.

Recebido em julho de 2018.

Aprovado em outubro de 2018. 